\title{
Identifikasi Struktur Batuan Daerah Vulkanik Gunung Api Awu Menggunakan Metode Geolistrik
}

\author{
Dolfie P. Pandaraa*, Ferdya* \\ aJurusan Fisika, FMIPA, Unsrat, Manado
}

KATA K U N I

Metode Geolistrik resistivitas, Konfigurasi Wenner-Schlumberger, Konfigurasi Dipol-dipol, Gunungapi Awu.

\begin{abstract}
A B S T R A K
Telah dilakukan penelitian untuk menentukan struktur perlapisan batuan daerah vulkanik GunungapiAwu di Kabupaten Kepulauan Sangihe Propinsi Sulawesi Utara. Metode yang digunakan dalam pengambilan data adalah metode geolistrik.Data-data yang akan dieskplorasi untuk menentukan struktur perlapisan batuan adalah variasi data resistivitas.Pengukuran nilai resistivitas menggunakan konfigurasi Wenner-Schlumberger dan Dipol-dipol, untuk mendapatkan resistivitas sesungguhnya dilakukan proses inversi dengan menggunakan bantuan software Res2Dinv.Penelitian dilakukan pada dua lokasi pengukuran dengan 2 lintasan pada lokasi pertama dan 3 lintasan pada lokasi kedua, disekitar daerah gunungapi Awu. Panjang setiap lintasan 480 meter dengan jumlah elektroda yang digunakan adalah 48 elektroda. Hasil yang diperoleh menunjukkan nilai resistivitas dimulai dari 2.39 hingga $16870 \mathrm{ohm}$ meter untuk lintasan 1. 5.36 - 5238 ohm meter untuk lintasan 2, 63.7 - 3771 ohm meter untuk lintasan 3, 54.9 - 3106 untuk lintasan 4, dan 38.5 13770 untuk lintasan 5.

A B S T R A C T

A Research has been conducted to determine the structure of volcanic rock bedding of Awu volcano area in Sangihe Islands Regency of North Sulawesi Province. The method used in data collection is the geoelectric method. The data to be explored to determine the structure of the bedding is the variation of resistivity data. The measurement of resistivity value using the configuration of Wenner-Schlumberger and Dipol-dipole, to obtain resistivity is actually done inversion process by using software assistance Res2Dinv.The research done on two measuring locations with 2 tracks on the first location and 3 tracks on the second location, around the volcano area. The length of each trajectory of 480 meters with the number of electrodes used is 48 electrodes. The result obtained shows the resistivity value starting from 2.39 to $16870 \mathrm{ohm}$ meters for the track 1; 5.36 - 5238 ohm meter for track 2; 63.7 - 3771 ohm meter for track 3; 54.9 - 3106 for track 4; and 38.5 - 13770 for track 5.
\end{abstract}

Geo-electrical Methods, Wenner-Schlumberger Configuration, Dipole-dipole configuration, Awu volcano
KE YW O R D S

TERSEDIA ONLINE

01 Februari 2018

1. Pendahuluan

Lapisan tanah suatu daerah tergantung dari kondisi geologi dan iklim. Hal tersebut menyebabkan struktur lapisan tanah desa Santiago dan Panenekan yang berada di kaki gunung awu beraneka ragam.Untuk mengetahui jenis perlapisan bawah permukaan, maka dilakukan eksplorasi geolistrik dengan mencari nilai resistivitas tiap lapisan pada daerah penelitian.
Metode geolistrik merupakan suatu metode yang memanfaatkan sifat kelistrikan bumi, dengan cara menginjeksikan arus listrik kebawah permukaan dan respon berupa potensial listrik. Metode ini baik memberikan gambaran mengenai struktur lapisan tanah bawah permukaan. Pendugaan dengan menggunakan metode geolistrik di dasarkan pada kenyataan bahwa material yang berbeda akan menunjukkan nilai tahanan jenis yang berbeda juga, jika dialiri arus listrik. Konfigurasi wennerschlumberger dan konfigurasi Dipol-dipol

*Corresponding author: Jurusan Fisika FMIPA UNSRAT, Jl. Kampus Unsrat, Manado, Indonesia 95115; Email address: ferdy.sagita12@gmail.com Published by FMIPA UNSRAT (2018) 
merupakan sistem akuisisi data dilapangan untuk mendapatkan gambaran variasi nilai resistivitas bawah permukaan secara horizontal.Berdasarkan latar belakang diatas maka dilakukan pengambilan data pada daerah penelitian dengan menggunakan konfigurasi wenner-schlumberger dan konfigurasi dipol-dipol.Busur Sangihe merupakan salah satu busur vulkanik paling aktif dilndonesia.Aktivitas vulkaniknya termanifestasi dengan adanya gunungapi aktif. Salah satu gunungapi aktif di busur Sangihe adalah Gunungapi Awu. Gunungapi Awu terletak di Pulau Sangihe Besar, Kabupaten Kepulauan Sangihe, PropinsiSulawesi Utara pada posisi 3,670 Lintang Utara dan 125,290 BT Bujur Timur dengan ketinggian $1320 \mathrm{~m}$ di atas permukaan laut (Gambar 1.1 dan Gambar 1.2).Aktivitas erupsinya terjadi pada tahun 1640-41, 1711, 1812, 1856, 1875, 1883,1885, 1892,1893, 1913, 1921, 1922, 1930, 1966, 1992, dan yang terakhir tahun2004 (Badan Geologi,2011). Aktivitas erupsi tersebut bersama dengan manifestasi vulkanik yang ada di permukaan seperti solfatara, fumarol dan mata air panas merepresentasikan potensi geotermal di Pulau Sangihe Besar.

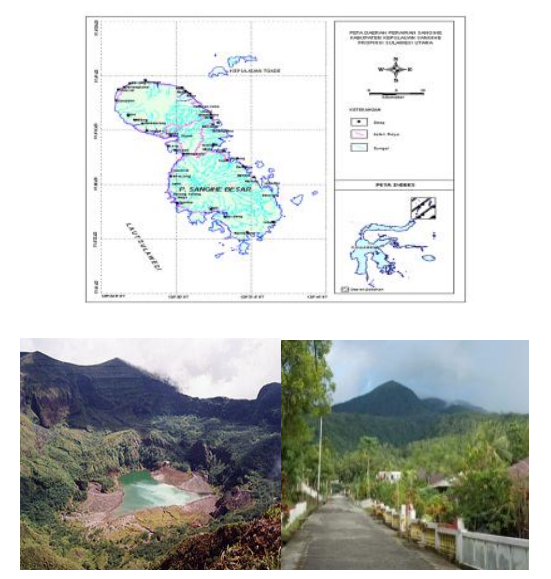

Gambar 1. Peta dan Foto Daerah Penelitian

Potensi geotermal sangat berkaitan dengan konveksi hidrotermal yang banyak dijumpai pada gunungapi aktif termasuk Gunungapi Awu. Di dekat permukaan gunungapi aktif selalu terdapat aliran massa magma dan air bawah tanah baik dingin maupun panas. Perubahan besar pada aktivitas vulkanik magma atau sumber air bawah tanah akan berkaitan langsung dengan aktivitas gunungapi. Aliran panas dari instruksi magmatik mempengaruhi suhu bawah permukaan sehingga membentuk sistem aliran air bawah tanah. Perubahan tersebut akan membangkitkan variasi medan potensial pada permukaan seperti gravitasi, pembangkitan listrik dan sifat magnetik. Salah satu pendekatan untuk memetakan konveksi hidrotermal yang kemungkinan berpotensi sebagai reservoir geotermal yaitu menggunakan data resistivitas listrik bawah permukaan. Metode geolistrik 2D DC Resistivity merupakan salah satu metode yang efisien untuk menggambarkan struktur bawah permukaan (As'ari,2012, HaerudinN.,V.J.Pardede, dan S. Rasimeng, 2099, Haerudin N.,S. Rasimeng dan E. Yuliana,2008, Fitterman, 1988; Finizola, 2003). Metode ini akan mengeksplorasi nilai resistivitas dari struktur tubuh gunung api.Persamaan matematis yang digunakan dalam menghitung resistivitas semudalam metode ini adalah:

$$
\rho a=\pi n(n+1)(1)
$$

Di mana $\rho$ amenyatakan resistivitas semu (ohm.m), $n$ menyatakan rasio jarakantaraelektroda C1-P1 dan P1-P2, a menyatakan spasi jarak antara P1 dan P2, $\checkmark$ menyatakan tegangan listrik (volt) dan I menyatakan arus listrik (mA).Untuk mendapatkan resistivitas sesungguhnya digunakan softwareRes2Dinv yang didasarkan pada metode smoothness-constrained least-squares(Constable et al, 1987) untuk memecahkan persamaan:

$$
(\boldsymbol{J} T \boldsymbol{J}+\alpha F) \boldsymbol{d}=\boldsymbol{J} T \boldsymbol{g}-\alpha \boldsymbol{F r}
$$

Di mana $F$ menyatakan matriks smoothing, $J$ menyatakan matriks Jacobiandariturunan parsial, $r$ menyatakan vektor yang mengandung logaritma dari nilai modelresistivitas, $\alpha$ menyatakan faktor damping, $\boldsymbol{d}$ menyatakan vektor model perturbasi,dang menyatakan vektor discrepancy. Vektor discrepancy mengandungperbedaan nilaii resistivitas semu terhitung dengan nilai resistivitas terukur.Besarnilai dari vektor tersebut didapatkan dengan menggunakan nilai root-meansquared (RMS).

\section{Material dan Metode \\ Metode Geolistrik Resistivitas}

Geolistrik adalah merupakan salah satu metode geofisika yang mempelajari sifat aliran listrik di bawah permukaan bumi.Pendeteksian di atas permukaan meliputi pengukuran medan potensial, arus, dan elektromagnetik yang terjadi baik secara alamiah maupun akibat penginjeksian arus kedalam bumi. Prinsip kerja metode geolistrik dilakukan dengan cara menginjeksikan arus listrik ke bawah permukaan bumi melalui sepasang elektroda dan mengukur beda potensial dengan sepasang elektroda yang lain. Bila arus listrik diinjeksikan ke dalam suatu medium dan diukur beda potensialnya (tegangan), maka nilai hambatan dari medium tersebut dapat diperkirakan. Berdasarkan pada tujuan penelitian yang dilakukan ini konfigurasi yang digunakan yaitu konfigurasi wenner-Schlumberger dan konfigurasi dipole-dipol, yang bertujuan mempelajari variasi resistivitas lapisan bawah permukaan bumi.

\section{Pengukuran Resistivitas Listrik}

Konfigurasi yang akan digunakan dalam pengambilan data resistivitas adalah konfigurasi Wenner-Schlumberger dan Dipol-dipol.Kedua konfigurasi ini memanfaatkan 4 elektroda, yaitu 2 elektroda arus dan 2 elektroda potensial. Arus diinjeksikan melalui elektroda arus dan beda potensial yang teramati akan dibaca oleh voltmeter. Sedangkan besarnya arus yang diinjeksikan dibaca oleh amperemeter. 
Peralatan yang akan digunakan dalam pengukuran ini adalah:Multichannel Resistivity, elektroda, take out cable dan aki kering. Data reisistivitas listrik akan digunakan untuk mencitrakan struktur bawah dari daerah vulkanik GunungapiAwu berdasarkan kontras resistivity.Akuisisi data resistivitas dibagi menjadi 5 lintasan yaitu: Lintasan 1 dan lintasan 2 dilokasi desa Santiago sedangkan lintasan 3, 4 dan 5 dilokasi desa Panenekan dengan jumlah elektroda 48 dan spasi antar elektroda $10 \mathrm{~m}$. Panjang lintasan mencapai $480 \mathrm{~m}$. Proses inversi dari data mentah resistivitas listrik diolah dengan perangkat lunak Res2Dinv. Hasil proses inversi ini akan ditampilkan dalam bentuk citra 2D. Melalui pengolahan data tersebut dapat diperoleh variasi nilai resistivitas terhadap kedalaman sehingga dapat diketahui ketebalan lapisan dan jenis batuan pada tiap-tiap titik pengukuran.

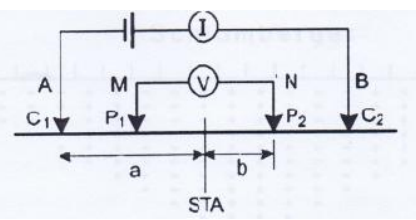

Gambar 2. Konfigurasi Wenner- Schlumberger

\section{Hasil Dan Pembahasan}

Penampang lintang hasil pengolahan data pada lintasan $1 \mathrm{~s} / \mathrm{d} 3$ diperlihatkan oleh gambar $1 \mathrm{~s} / \mathrm{d} 3$ yangterdiri dari bagian pseudosectionresistivitas terukur (measured apparent resistivity pseudosection), dan model resistivitashasil inversi. Pseudosectionresistivitas terukur diperoleh dari hasil pengukuran di lapangan dengan data yang diperoleh yaitu beda potensial $(V)$, berdasarkan kuat arus (I) yang diinjeksikankebawah permukaan bumi, sehingga diperoleh nilai ( $\rho$ a). Pseudosection resistivitas terhitung merupakan hasilpemodelan ke depan oleh software RES2DINV yang akan menjadi model awal untuk proses inversi. Dalam proses inversi, respon model dibandingkan dengan respon data lapangan. Jika berbeda jauh maka model(parameter) diubah sampai mendekati data struktur bawah permukaan yang sebenarnya. Proses pengubahan model ini dilakukan secara otomatis oleh software, sehingga nilai optimum dalam proses inversi dicapai apabila error yang dihasilkan sekecil mungkin.

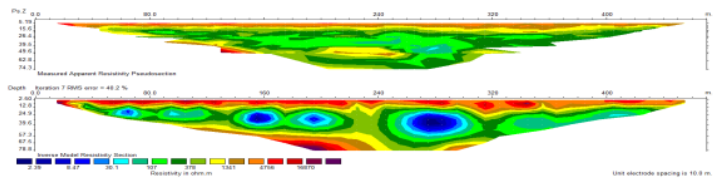

Gambar 3. Penampang Lintang Lintasan 1 Nilai Resistivitas Batuan Daerah Vulkanik gunungapi Awu

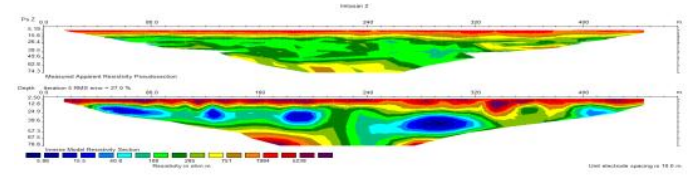

Gambar 4. Penampang Lintang Lintasan 2 Nilai Resistivitas Batuan Daerah Vulkanik gunungapiAwu

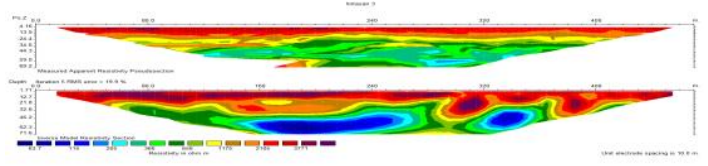

Gambar 5. Penampang Lintang Lintasan 3 Nilai Resistivitas Batuan Daerah Vulkanik gunungapi Awu

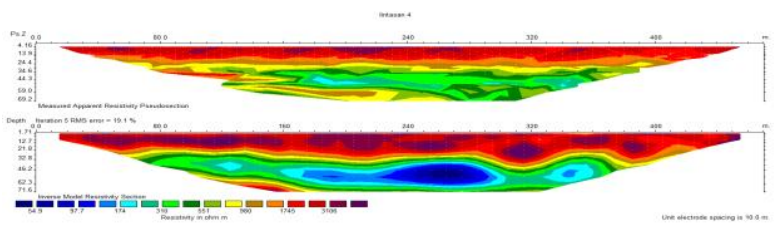

Gambar 6. Penampang Lintang Lintasan 4 Nilai Resistivitas Batuan Daerah Vulkanik gunungapi Awu

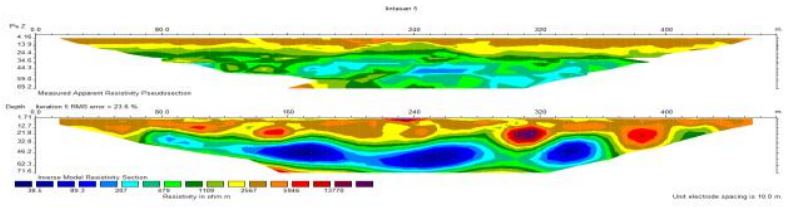

Gambar 7. Penampang Lintang Lintasan 5 Nilai Resistivitas Batuan Daerah Vulkanik gunungapi Awu

Berdasarkan penampang sebaran nilai resistivitas batuanpada lintasan1 dan 2 pada gambar diatas menunjukkan bahwa di daerah ini terdapat nilai resistivitas sangat rendah $(<10 \mathrm{ohm}$ m) dijumpai mulai pada kedalaman 24.9 m.zona sangat konduktif ini akan terbentuk bila terdapat fluida air, dalam keadaan panas yang tinggi.Karena kenaikan suhu dan tekanan menyebabkan nilai resistivitas batuan akan berkurang sehingga menjadi kecil yang diperkirakan tersusun dari lapisan batuan tufaan. Sedangkan pada permukaan sampai kedalaman $12.8 \mathrm{~m}$ dijumpai lapisan batuan dengan nilai resistivitas 4756 ohm meter untuk lintasan 1 dan 5238 ohm meter untuk lintasan 2, nilai ini diperkirakan tersusun dari lapisan jenis batu pasir, selain itu juga pada kedalaman $39.6 \mathrm{~m}$ untuk lintasan 1 dijumpai lapisan batuan yang mempunyai nilai resistivitas 107 ohm m, 378 ohm m dan 1341 ohm $\mathrm{m}$ yang diperkirakan terdiri dari jenis kerikil dan batu pasir. Demikian juga untuk lintasan 2 pada kedalaman yang sama di jumpai lapisan jenis yang sama pada lintasan 1. Pada lintasan 3 pada kedalaman $21.8 \mathrm{~m}$ mempunyai nilai resistivitas 1175 ohm m, 2105 ohm m dan 3771 ohm m, yang diperkirakan jenis lapisan batu pasir. Sedangkan pada kedalaman $32.8 \mathrm{~m}$ sampai $71.6 \mathrm{~m}$ 
diperlihatkan dengan nilai resistivitas $63.7 \mathrm{ohm} \mathrm{m}$, 114 ohm m, 205 ohm m,366 ohm m dan 656 ohm $\mathrm{m}$. yang diperkirakan mempunyai jenis lapisan lempung dan alluvium. Pada lintasan 4 bagian mulai dari permukaan di dominasi oleh batu pasir kemudian kerikil dan lempung, alluvium dan batu tufaan.Sedangkan untuk lintasan 5 dimulai dari nilai resistivitas 38.5 ohm m hingga 13770 ohm m. yang didominasi oleh jenis lapisan Alluvium, lempung, batu pasir, hingga batuan basalt.

\section{Kesimpulan}

Dari bahasan hasil di atas disimpulkan:

1. Nilai resistivitas sangat rendah $(<10 \mathrm{Ohm} \mathrm{m})$ dijumpai pada permukaan sampai kedalaman $24.9 \mathrm{~m}$. Zona ini sangat konduktif disebabkan oleh adanya fluida air.

2. Nilai resistivitas dengan nilai resistivitas yang besar terdapat pada permukaan lapisan, yang diperkirakan merupakan endapan dari sisa-sisa letusan gunungapi Awu.

\section{Daftar Pustaka}

Telford, W.M., Gedaart, L.P.,Sheriff, R.E., 1990, Applied Geophysics, Cambridge, NewYork.

Reynolds, J.M., 1997, AnIntroduction to Applied andEnviromental Geophysics, John Willey and Sons, New York.

William J. Johnson, 2003, Applications Of The Electrical Resistivity Method For Detection Of Underground Mine Workings, Geophysical Technologies for Detectin Underground Coal Mine Voids, Lexington, KY, July 28-30.

Burger, Henry Robert. 1992. Exploration Geophisics Of The Shallow Subsurface. New Jersey: Prentice Hall.

Firdaus, Djadjuli. 1984. Aplikasi Geolistrik Tahanan Jenis Untuk Eksplorasi Panas Bumi.

Diktat Geologi Pertambangan dan Mineralogi,LIPI: Bandung

Robinson \& Coruh. 1998. Basic Exploration Geophysic. John Willey and Son,Inc. Canada

Santoso, Djoko. 1995. Diktat Kuliah TG-424 Eksplorasi Energi Panas Bumi. Jurusan Teknik Geologi ITB: Bandung

A'sari, 2012.Pemetaan Akuifer Air Tanah di Kecamatan Prambanan Kabupaten Sleman Daerah Istimewa Yogyakarta dengan Menggunakan Metode Geolistrik Tahanan Jenis.JURNAL MIPA UNSRAT ONLINE 1 (1) 37 44, ISSN 2302-3899,Vol. 1 No.1 Agustus 2012

Badan Geologi. 2011. Data Dasar Gunungapi Indonesia. Edisi Kedua. Kementerian Energi dan Sumber Daya Mineral Republik Indonesia

Bai, L., D.R. Baker, and R.J. Hill. 2010. Permeability of vesicular Stromboli basaltic glass: Lattice Bolztmann simulations and laboratory measurements.Journal of Geophysical Research 115 (B07201):1-16

Fitterman, D.V., W.D. Stanley, R.J. Bisdorf. 1988. Electrical structure of Newberry volcano, Oregon. J. Geophysics Re.,93,10, 119 - 134
Finizola A., et al, 2003. The summit hydrothermal system of Stromboli.New insights from selfpotential, temperature, $\mathrm{CO} 2$ and fumarolic fluid measurements with structural and monitoring implications. Journal of Volcanology and Geothermal Research

Haerudin N, V.J. Pardede, dan S. Rasimeng, 2009. Analisis Reservoar Daerah Potensi Panasbumi Gunung RajabasaKalianda dengan Metode tahanan jenis dan Geotermometer. Jurnal IImu Dasar, Vol 10 No.2, 141-146

Hase, H.,et al, 2004. Hydrothermal system beneath Aso Volcano as inferred from Self-Potential Mapping and Resistivity Structure.Journal of Volca 